\title{
Selection of Fusion Level for Adolescent Idiopathic Scoliosis Surgery : Selective Fusion versus Postoperative Decompensation
}

\author{
Do-Hyoung Kim, Seung-Jae Hyun, Ki-Jeong Kim \\ Department of Neurosurgery, Spine Center, Seoul National University Bundang Hospital, Seoul National University College of Medicine, \\ Seongnam, Korea
}

Adolescent idiopathic scoliosis (AIS), which is associated with an extensive range of clinical and radiological presentations, is the one of the most challenging spinal disorders. The goals of surgery are to correct the deformity in 3 dimensions and to preserve motion segments while avoiding complications. Despite the ongoing evolution of classification systems and algorithms for the surgical treatment of AIS, there has been considerable debate regarding the selection of an appropriate fusion level in AIS. In addition, there is no consensus regarding the exact description, relationship, and risk factors of coronal decompensation following selective fusion. In this review, we summarize the current concepts of selection of the fusion level for AIS and review the available information about postoperative coronal decompensation.

Key Words : Adolescent idiopathic scoliosis · Spinal fusion · Selective fusion · Coronal decompensation.

\section{INTRODUCTION}

Adolescent idiopathic scoliosis (AIS) is a complex 3-dimensional spinal deformity. The main goal of the surgical treatment of AIS should be to achieve coronal and sagittal balance and preservation of motion segments, while avoiding complications such as curve progression, coronal decompensation, junctional kyphosis, adding-on, and the need for revision surgery $^{10,14,22,41,52,58,60)}$. There has been considerable debate about the adequacy of selective spinal fusion for AIS. With the development of classification systems and instrumentation tech- niques, the guidelines for treating AIS have undergone significant changes. The goal has now shifted to minimizing the number of fusion segments and maximizing the number of unfused motion segments, expecting that the unfused curve will spontaneously accommodate to compensate for the corrected position of the fused curve ${ }^{4)}$. Although spontaneous correction of the unfused curve can be achieved after selective fusion, postoperative decompensation remains a troublesome problem. Even with a precise interpretation of the curvature and determination of proper fusion level, there are also many cases of postoperative decompensation. Despite the wide-

- Received : September 2, 2020 •Revised : September 27, 2020 •Accepted : October 9, 2020

- Address for reprints : Seung-Jae Hyun

Department of Neurosurgery, Spine Center, Seoul National University Bundang Hospital, Seoul National University College of Medicine, 82 Gumi-ro 173beon-gil, Bundang-gu, Seongnam 13620, Korea

Tel : +82-31-787-7169, Fax : +82-31-787-4097, E-mail : hyunsj@snu.ac.kr, ORCID : https://orcid.org/0000-0003-2937-5300

This is an Open Access article distributed under the terms of the Creative Commons Attribution Non-Commercial License (http://creativecommons.org/licenses/by-nc/4.0) which permits unrestricted non-commercial use, distribution, and reproduction in any medium, provided the original work is properly cited. 
spread interest in correcting coronal deformities, there are discrepancies in the literature regarding the definition of coronal decompensation, and relevant risk factors have not been conclusively established. In this study, based on a literature review, we describe the current concepts of selective fusion in AIS, evaluate the available information on the postoperative development of coronal decompensation, and summarize the outcomes of this complication and related factors.

\section{MATERIALS AND METHODS}

In this review, published clinical studies and review articles dealing with selective fusion as a means of surgical treatment for AIS were included. PubMed, Scopus, Web of Science, and Google Scholar were searched from inception through May 2020 using a predefined search strategy. The following key words were searched in the databases : "adolescent idiopathic scoliosis," "selective fusion," "selection of fusion level," "coronal decompensation," and various combinations of these terms. A total 68 studies were identified. Case reports and articles that did not focus on the selection of the fusion level and postoperative changes were excluded. Finally, 28 articles were included in this systematic review. The radiological parameters mentioned in this article are summarized in Fig. 1.

\section{HISTORY AND CRITERIA FOR SELECTIVE FU- SION}

Corrective surgery for AIS can provide several benefits to affected patients, including improvements in quality of life, disability, back pain, psychological well-being, and breathing function. According to Ward et al. ${ }^{57)}$, who compared the outcomes of 190 non-operatively treated AIS patients with those of 166 operatively treated patients, statistically significant differences were found in self-image, satisfaction, and total score in favor of the operative cohort. However, in many previous studies, lower back pain and disability occurred over the course of long-term follow-up in patients who had long level AIS surgery. This was related to degenerative disc disease, a late complication. Based on the study of Akazawa et al. ${ }^{1}$, who investigated the long-term (average follow-up period : 35 years) incidence of lumbar disc degeneration and Modic
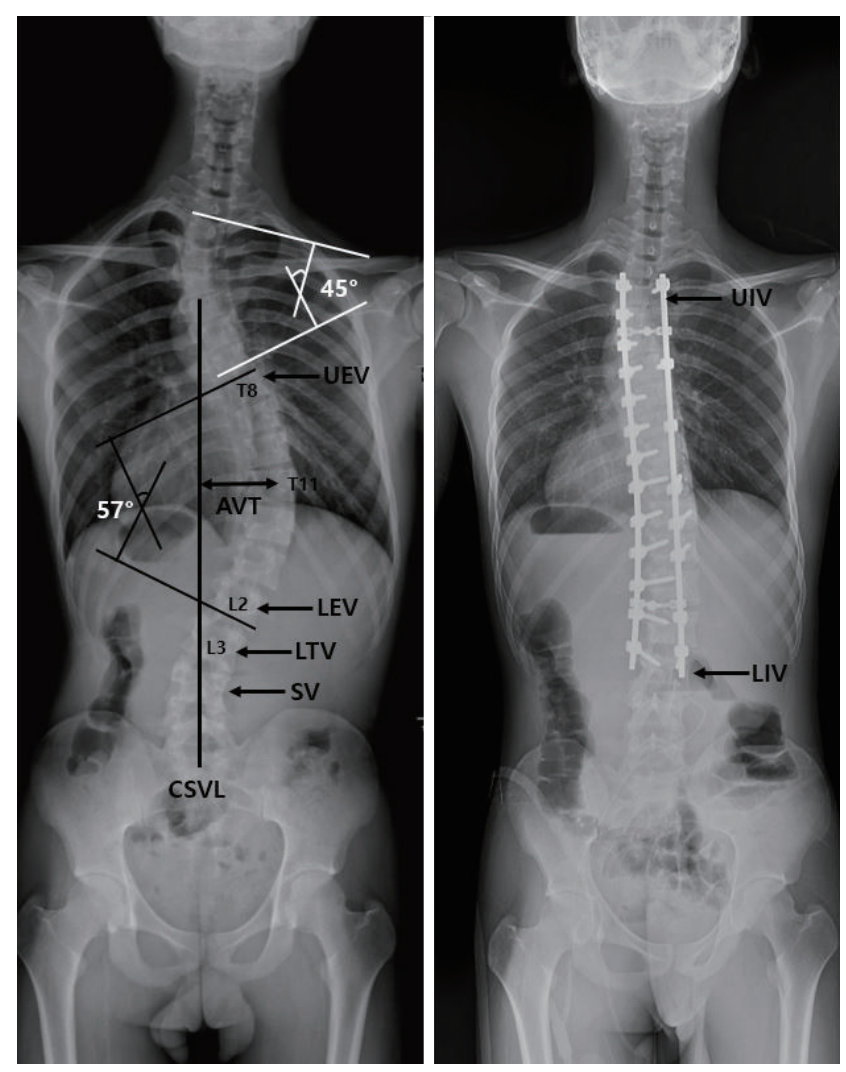

Fig. 1. Definition of the radiographic parameters. The Cobb angle of thoracic major curve and proximal thoracic curve is $57^{\circ}$ and $45^{\circ}$, respectively. Upper end vertebra (UEV) means the upper vertebra that is most tilted from the horizontal apical vertebra. Apical vertebral translation (AVT) means the distance from the CSVL to the mid-point of the apical vertebra. Lower end vertebra (LEV) means the lower vertebra that is most tilted from the horizontal apical vertebra. Last touched vertebra (LTV) means the most proximal vertebra that are touched by the CSVL. Stable vertebra (SV) means the vertebra that are bisected or nearly bisected by the CSVL. Central sacral vertical line (CSVL) means the vertical line that bisects proximal sacrum. UIV : upper instrumented vertebra, LIV : lower instrumented vertebra.

changes in the non-fused segments of patients with AIS who previously underwent spinal fusion, it is recommend for the lowest fusion level to be L3 or higher in order to reduce the risk of disc degeneration in midlife. Selective fusion is a concept that has developed in relation to these problems and is defined in this review as selective thoracic fusion (STF) for thoracic curves and selective thoracolumbar/lumbar (TL/L) curves.

In 1958, Moe $^{36)}$ first introduced the concept of STF for a primary thoracic curve with a compensatory lumbar curve and noted that the curve pattern suitable to STF was characteristically a primary right thoracic curve with a left lumbar 
curve, being structural but not as inflexible as a thoracic curve with bending to the side. The surgical treatment of AIS has made remarkable progress since the development of the Harrington rod in the late $1950 \mathrm{~s}^{15)}$. King and colleagues ${ }^{27)}$ stated that successful STF, with the lower instrumented vertebra (LIV) at the neutral vertebra (NV) and stable vertebra (SV), was performed using Harrington instrumentation with spontaneous correction of the lumbar compensatory curve in a King-Moe type II curve. The King-Moe classification of idiopathic thoracic scoliosis is a long-standing system widely used to classify curve patterns and to recommend fusion levels. However, a limitation of this system is that it is based only on the coronal plane, lacks a defined isolated thoracolumbar curve type, and has relatively poor to fair inter-observer and intra-observer reliability ${ }^{12,31)}$.

In 2001, to overcome the limitations of the King-Moe classification, Lenke et al. ${ }^{31}$ introduced a new classification system that redefined the way in which arthrodesis levels are selected. The classification combines six coronal curve patterns (1 through 6) with three lumbar modifiers (A, B, or C) and three sagittal thoracic modifiers (minus, normal, or plus), and requires not only standing coronal and lateral full-spine radiographs, but also supine side-bending films. The spinal column regions to be evaluated in this system are proximal thoracic (PT), main thoracic (MT), and TL/L. The major curve that has the largest Cobb angle should always be included in the fusion. If the curve is regarded as being nonstructural (corrects to $<25^{\circ}$ as measured on side-bending radiographs and/or kyphosis of $<20^{\circ}$ between T2 -5 and T10-L2), it does not have to be included in the fusion. The authors proposed radiographic criteria that should be considered when evaluating a patient for STF or TL/L fusion. The thoracic apical vertebral translation (AVT) is the distance between the C-7 plumb line and the center of the apical vertebral body of the thoracic curve. The TL/L AVT is the distance between the center of the apical vertebral body of the TL/L and the central sacral vertebral line $(\mathrm{CSVL})^{55)}$. The other factor that helps in the decision of whether selective fusion is possible is apical vertebral rotation (AVR), which is based on the Nash-Moe grading for vertebral rotation ${ }^{37)}$. They recommended STF for structural curves to treat Lenke 1C curves if the ratios of MT : TL/L Cobb angle, AVT-MT : AVT-TL/L, and AVR-MT : AVR-TL/L are $>1$.2. Conversely, the recommended ratio for these parameters for selective TL/L fusion should be $>1.25$ (Tables 1 and 2) ${ }^{33)}$.
However, these guidelines are not routinely accepted and have several limitations. In Lenke 1C curves, Newton and colleagues $^{38)}$ reported that only two-thirds of experienced surgeons would perform STF, and Crawford et al. ${ }^{6}$ noted that only 49\% (138/264) of patients underwent STF in their series; thus, the Lenke lumbar $\mathrm{C}$ modifier was termed as a "rule breaker." In addition, the Lenke classification has no lowest or uppermost instrumented vertebra criteria and poor inter-observer reliability in the PT curve.

\section{STF}

\section{Upper instrumented vertebra (UIV)}

The preservation of motion is a less important factor in the selection of the UIV because the thoracic spine is rigid by nature due to the stabilizing effects of the rib cage and the sternum. Selection of the UIV is important for shoulder balance, proximal curve progression, and proximal junctional kyphosis. Several studies have attempted to establish the best predictors of the need for fusion of the PT curve ${ }^{19,25)}$. If the PT curve is structural, should the PT curve be included in fusion? Up to what level should fusion be performed?

Lee and colleagues ${ }^{29)}$ proposed that both the PT and the MT curves should be fused when the left shoulder was elevated or PT curves were rigid, as the correction and fusion of the lower thoracic curve aggravated shoulder balance. However, this strategy has changed due to advent of strong instrumentation systems. Lenke et al. ${ }^{32)}$, who used Cotrel-Dubousset instrumentation defined criteria for inclusion of the PT curve in the fusion. These criteria included curve magnitude $>30^{\circ}$ and $>25^{\circ}$ on bending radiographs, AVR $\geq$ Nash-Moe grade 1 , AVT $>1 \mathrm{~cm}$, elevation of the left shoulder or tilt of T1 into the concavity of the PT curve, or location of the transitional vertebra between the two thoracic curves at T6 or lower. In 2000, Suk et al. ${ }^{49)}$ recommended that the idiopathic thoracic scoliosis with a PT curve of more than $25^{\circ}$ and a level or elevated left shoulder should be considered a double thoracic curve pattern and should be treated by fusion of both the proximal and the distal curves. Kuklo and colleagues ${ }^{28)}$ retrospectively evaluated radiographic parameters associated with the PT curve to determine whether these characteristics could be used to predict postoperative shoulder balance. The authors concluded that spontaneous PT curve correction consistently occurs after instrumented correction of the MT curve. Furthermore, preop- 
erative side-bending radiographs (PT curve flexibility) are positively correlated with postoperative spontaneous PT curve correction. Because of the spontaneous correction of PT curves, some authors remain skeptical about the extension of fusion to $\mathrm{T} 2$ or $\mathrm{T} 3$ in cases of nonstructural PT curves ${ }^{5}$. Cil et al. ${ }^{5)}$ reviewed the Lenke criteria in their series of patients with

Table 1. Factors to consider in selective fusion of thoracic curves

\begin{tabular}{|c|c|c|}
\hline Category & Criteria & Note \\
\hline Candidates & Lenke $1 C, 2 C, 3 C, 4 C$ & \\
\hline \multirow[t]{3}{*}{ Clinical parameters } & Lifestyle and activity level & \\
\hline & Thoracic rotational prominence $>$ lumbar prominence & \\
\hline & Soft tissue flexibility : thumb abduction test & \\
\hline \multicolumn{3}{|l|}{ Radiographic parameters } \\
\hline \multirow[t]{6}{*}{ Coronal plane ratio criteria } & AVT thoracic $>1.2$ & Possible if AVT criteria only \\
\hline & AVT thoracolumbar/lumbar $>1.2$ & Better if 2 or 3 criteria met \\
\hline & AVR thoracic $>1.2$ & \\
\hline & AVR thoracolumbar/lumbar $>1.2$ & \\
\hline & Thoracic Cobb angle $>1.2$ & \\
\hline & Thoracolumbar/lumbar Cobb angle $>1.2$ & \\
\hline \multirow[t]{2}{*}{ Sagittal plane criteria } & Thoracolumbar (T10-L2) kyphosis $<10^{\circ}$ & \\
\hline & Sagittal disc angle below LIV : lordosis & \\
\hline Skeletal maturity & Triradiate cartilage : closed & \\
\hline \multirow[t]{3}{*}{ Additional criteria } & $\mathrm{TL} / \mathrm{L}$ side bending $<25^{\circ}$ & Possible if $T L / L$ side bending $>25^{\circ}$ if more criteria are met \\
\hline & $\mathrm{TL} / \mathrm{L}$ curve $<60^{\circ}$ & \\
\hline & CSL touches thoracic LEV or below & \\
\hline
\end{tabular}

AVT : apical vertebral translation, AVR : apical vertebral rotation, LIV : lower instrumented vertebra, TL/L : thoracolumbar/lumbar, CSL : central sacral vertical line, LEV : lower end vertebrae

Table 2. Factors for to consider in selective fusion of lumbar curves

\begin{tabular}{lll}
\hline Category & \multicolumn{1}{c}{ Criteria } & Note \\
\hline Candidates & Lenke 5 C, $6 C$ & \\
Clinical parameters & Lifestyle and activity level & \\
& Lumbar rotational prominence $>$ thoracic prominence & \\
& Soft tissue flexibility : thumb abduction test & \\
Radiographic parameters & & Possible if AVT criteria only \\
Coronal plane ratio criteria & AVT thoracolumbar/lumbar $>1.25$ & Better if 2 or 3 criteria met \\
& AVT thoracic $>1.25$ & \\
& AVR thoracolumbar/lumbar $>1.25$ & \\
& AVR thoracic $>1.25$ & \\
& Thoracolumbar/lumbar Cobb angle $>1.25$ & \\
Sagittal plane criteria & Thoracic Cobb angle $>1.25$ & Thoracolumbar (T10-L2) kyphosis $<10^{\circ}$ \\
Skeletal maturity & Triradiate cartilage : closed & Possible if $>25^{\circ}$ if more criteria met \\
Additional criteria & TL/L side bending $<25^{\circ}$ & Possible if $>40^{\circ}$ if T10-L2 $>20^{\circ}$ if UIV $\geq T 10$ \\
\hline
\end{tabular}

AVT : apical vertebral translation, AVR : apical vertebral rotation, UIV : upper instrumented vertebra, TL/L : thoracolumbar/lumbar 
nonstructural PT curves, some of whom had undergone PT fusion. They concluded that there was no difference in terms of outcomes between including a nonstructural PT curve into the area of fusion or solely fusing the MT curve, meaning that extension of fusion to T2 or T3 is unnecessary. However, shoulder balance was not specifically assessed.

In 2008, Ilharreborde et al. ${ }^{19)}$ agreed with the earlier conclusion by Lee et al. ${ }^{29)}$ that no relationship exists between $\mathrm{T} 1$ tilt and that fusion for the entire PT curve is not necessary for every double thoracic curve, and therefore recommended fusion of structural PT curves and nonstructural PT curves if T1 tilt and shoulder balance are in the same direction and would be worsened with correction of the main curve. If shoulder tilt and T1 tilt are in opposite directions, they suggested that instrumentation of only the part of the upper thoracic curve (T2 or T3) would be possible ${ }^{19)}$. Elfiky and colleagues ${ }^{9)}$ proposed that spontaneous correction of the PT curve after fusion of the MT curve occurs in structural curves greater than $35^{\circ}$ and less than $45^{\circ}$. Thus, a non-fusion strategy may be appropriate for PT curves between $35^{\circ}$ and $45^{\circ}$. The results of studies on UIV selection in AIS with thoracic curves are summarized in Table 3.

In summary, many studies have been conducted to deter- mine the appropriate UIV of thoracic major curves. Based on the results of the studies so far, several review articles have recommended the following. If the PT curve is structural, the UIV is T2 for preoperative left shoulder elevation, T3 for preoperative level shoulders, and $\mathrm{T} 4$ for preoperative right shoulder elevation. If the PT curve is nonstructural, the UIV is the upper end vertebra (UEV) of the thoracic major+2 (2 vertebrae proximal) for preoperative left shoulder, UEV+1 (1 vertebra proximal) for preoperative level shoulder and the UEV for preoperative right shoulder elevation ${ }^{10,25,26,54)}$. However, no consensus guidelines about selection of the UIV, surgical methodology, and risk factors for shoulder imbalance and proximal junctional kyphosis have been established. Longterm studies and methodological research are needed to determine the selection of the appropriate UIV for STF.

\section{Lower instrumented vertebra}

Although long-term follow-up data on selecting the distal fusion level are scarce, it is generally accepted that the area of spinal fusion should be as short as possible. Selection of the appropriate LIV is important in avoiding distal junctional problems such as distal junctional kyphosis (DJK) and adding-on ${ }^{11}$.

Table 3. Summary of the literature on UIV selection in AIS with thoracic curves

\begin{tabular}{|c|c|c|c|c|c|}
\hline Study & Curve type & $\begin{array}{l}\text { Total No. } \\
\text { of patients }\end{array}$ & $\begin{array}{l}\text { Mean age } \\
\text { (years) }\end{array}$ & $\begin{array}{l}\text { Mean } \\
\text { follow-up } \\
\text { (years) }\end{array}$ & Conclusion \\
\hline Lee et al. ${ }^{29)}$ (1993) & Thoracic major curves & 246 & 15.9 & 4.8 & $\begin{array}{l}\text { PT and MT curves should be fused when the left shoulder } \\
\text { is elevated or there is a rigid upper thoracic curve. }\end{array}$ \\
\hline Lenke et al. ${ }^{32)}$ (1994) & King type 3 & 27 & 15 & 3 & $\begin{array}{l}\text { PT curve fusion should be extended to T2 when the PT } \\
\text { curve is }>30^{\circ} \text { and }>20^{\circ} \text { on bending radiographs. }\end{array}$ \\
\hline Suk et al. ${ }^{49)}(2000)$ & PT curve $>25^{\circ}$ & 40 & 15.9 & 3.1 & $\begin{array}{l}\text { If PT curve }>25^{\circ} \text {, level or elevated left shoulder, PT curve } \\
\text { should be treated with fusion. }\end{array}$ \\
\hline Kuklo et al. ${ }^{28)}(2001)$ & PT curve $>20^{\circ}$ & 85 & 14.5 & 3.6 & $\begin{array}{l}\text { PT curve should be left unfused if the PT curve is flexible. } \\
\text { Spontaneous PT curve correction consistently occurs } \\
\text { after instrumentation of the main thoracic curve. }\end{array}$ \\
\hline Cil et al. ${ }^{5)}(2005)$ & $\begin{array}{l}\text { Non-structural PT } \\
\text { curve (side bending } \\
\text { Cobb }<25^{\circ} \text { ) }\end{array}$ & 37 & 15 & 4.8 & $\begin{array}{l}\text { In non-structural PT curves, extension of fusion to T2 or T3 } \\
\text { is unnecessary. }\end{array}$ \\
\hline Ilharreborde et al. ${ }^{19)}$ (2008) & Lenke type 1, 2 & 132 & 15.2 & 2.5 & $\begin{array}{l}\text { Structural PT curves should be fused. If shoulder tilt and T1 } \\
\text { tilt are in the same directions, non-structural PT curves } \\
\text { should be fused. }\end{array}$ \\
\hline Elfiky et al.9) (2011) & PT curve $>35^{\circ}$ & 30 & 16.2 & 3 & $\begin{array}{l}\text { A non-fusion strategy may be appropriate for PT curves } \\
\text { between } 35^{\circ} \text { and } 45^{\circ} \text {. }\end{array}$ \\
\hline
\end{tabular}

UIV : upper instrumented vertebra, AIS : adolescent idiopathic scoliosis, PT : proximal thoracic, MT : main thoracic 
Before the development of instrumentation techniques, fusion from the end to end vertebra $(\mathrm{EV})$ with neutral rotation was recommended as the ideal LIV for AIS to prevent the adding-on phenomenon ${ }^{11,50)}$. In 1983, King et al. ${ }^{27)}$ recommended the SV, which is the distal vertebra most bisected by CSVL, as the LIV when using Harrington rods. However, this recommendation became less applicable with the introduction of more powerful segmental instrumentation systems ${ }^{53)}$. With the increased use of thoracic pedicle screws, the LIV selection criteria have been discussed by several authors. Suk et al. $^{50)}$ suggested that the LIV should be selected based on the relative position of the NV. They recommended selecting the $\mathrm{NV}$ when it was the same or 1 level distal to the EV of the main curve and NV-1 if 2 or more levels separated the EV from the $\mathrm{NV}^{50)}$. Parisini and colleagues ${ }^{40)}$ considered the rotation of the lumbar vertebra just below the lower thoracic EV as an important factor, like the SV position, for determining fusion levels in single thoracic curves where the lumbar compensatory curve does not cross the middle line. If the rotation of the first vertebra just below the EV is in the same direction as the thoracic curve, and if the SV and EV have a difference of $>2$ levels, then distal fusion to L2 or L3 is recommended.

Table 4. Summary of the literature on LIV selection in AIS with thoracic curves

\begin{tabular}{|c|c|c|c|c|c|}
\hline Study & Curve type & $\begin{array}{l}\text { Total No. } \\
\text { of patients }\end{array}$ & $\begin{array}{c}\text { Mean age } \\
\text { (years) }\end{array}$ & $\begin{array}{l}\text { Mean } \\
\text { follow-up } \\
\text { (years) }\end{array}$ & Conclusion \\
\hline Suk et al. ${ }^{50)}(2003)$ & King type 3, 4 & 42 & 15.5 & 4.2 & $\begin{array}{l}\text { When preoperative NV and EV show no more than a 2-level } \\
\text { gap, fusion should be extended down to NV. When the } \\
\text { gap is more than } 2 \text { levels, fusion should be extended } \\
\text { down to NV-1. }\end{array}$ \\
\hline
\end{tabular}

\begin{tabular}{|c|c|c|c|c|c|}
\hline Parisini et al. ${ }^{40)}(2009)$ & Lenke type $1 \mathrm{~A}$ & 31 & 16.3 & Min. 2 & $\begin{array}{l}\text { If the rotation just below the thoracic LEV is in the same } \\
\text { direction as the thoracic curve, and SV and EV show } \\
\text { >-level differences, fusion should extended to L2 or L3. } \\
\text { Otherwise, SV-2 or SV-3 should be the distal fusion level. }\end{array}$ \\
\hline Wang el al. ${ }^{56)}(2011)$ & Lenke type $1 \mathrm{~A}$ & 45 & - & 3.6 & $\begin{array}{l}\text { Choosing the first vertebra in the cephalad direction from } \\
\text { sacrum whose deviation from CSVL is more than } 10 \mathrm{~mm} \\
\text { as the LIV provides the best outcomes. }\end{array}$ \\
\hline Sarlak et al. ${ }^{45)}$ (2011) & Lenke type $1 \mathrm{~A}$ & 36 & 15.8 & 4.3 & $\begin{array}{l}\text { The distal fusion level should be extended to LEV }-1 \text { in } \\
\text { cases of neutral } L 3 \text { vertebra and to the LEV in cases of } L 3 \\
\text { vertebral tilt. }\end{array}$ \\
\hline Takahashi et al. ${ }^{52)}$ (2011) & Lenke type $1 B, 1 C, 3 C$ & 172 & 14 & 2 & $\begin{array}{l}\text { If the SV is below the EV, the LIV should be chosen at least } \\
1 \text { level distal to the SV. If the SV and the EV are the same, } \\
\text { the LIV is recommended to be } 1 \text { level below the SV/EV. }\end{array}$ \\
\hline Matsumoto et al..$^{35)}$ (2013) & Lenke type $1 \mathrm{~A}$ & 112 & 16.1 & 3.6 & $\begin{array}{l}\text { Fusion should be extended at least to the LTV to avoid } \\
\text { postoperative AO. }\end{array}$ \\
\hline Hyun et al. ${ }^{17)}$ (2015) & Lenke type 1, 2, 3, 4 & 76 & 14.7 & 3.2 & $\begin{array}{l}\text { To prevent } A O \text { or DJK following PSF to } L 3 \text {, the CSVL should } \\
\text { touch } L 3 \text { on upright and bending films, the } L 3 / 4 \text { disC } \\
\text { should be flexible, } L 3 \text { should be neutral }\left(<15^{\circ}\right) \text { and } \leq 2 \\
\mathrm{~cm} \text { from the } C S V L \text {, and patients should be } \geq \text { Risser } 2 \text {. }\end{array}$ \\
\hline Fischer et al. ${ }^{11)}(2018)$ & Lenke type 1, 2 & 544 & 14.7 & 4.1 & $\begin{array}{l}\text { The LIV should be the LTV or within } 2 \text { levels proximal to the } \\
\text { NV. }\end{array}$ \\
\hline Shen et al. ${ }^{46)}$ (2018) & Lenke type $1 \mathrm{~A}$ & 55 & 14.2 & Min. 2 & $\begin{array}{l}\text { Choosing either the SV and LSTV as the LIV can yield } \\
\text { satisfactory correction results. }\end{array}$ \\
\hline Qin et al. ${ }^{42)}(2020)$ & Lenke type 2A & 101 & 14.9 & Min. 2 & $\begin{array}{l}\text { The fusion level should be extended to the LSTV in } 2 A-R(L 4 \\
\text { tilt to right) curves and to } 1 \text { level distal from the LSTV in } \\
2 A-L(L 4 \text { tilt to left) curves. }\end{array}$ \\
\hline
\end{tabular}

LIV : lower instrumented vertebra, AIS : adolescent idiopathic scoliosis, NV : neutral vertebra, EV : end vertebra, Min. : minimum, LEV : Iower end vertebra, SV : stable vertebra, CSVL : center sacral vertical line, LTV : last touched vertebra, AO : adding-on phenomenon, DJK : distal junctional kyphosis, PSF : posterior spinal fusion, LSTV : last substantially touched vertebra 
However, if the rotation of the first vertebra just below the EV is in the opposite direction, and if SV and EV show a difference of $\leq 2$ levels, then SV-2 or SV-3 can be selected as the LIV. Wang et al. ${ }^{56)}$, who previously reported that the selection of the LIV was closely correlated with the presence of the addingon phenomenon, suggested that choosing the first vertebra in the cephalad direction from the sacrum whose deviation from the CSVL is more than $10 \mathrm{~mm}$ as the LIV provides the best outcomes, as doing so both prevents adding-on and conserves more lumbar motion and growth potential. Sarlak and colleagues ${ }^{45)}$ argued that the tilt of L3 and L4 in the coronal plane may play a significant role in determining the distal fusion level in Lenke 1A curves. They recommended that the distal fusion level should be extended to at least lower end vertebra (LEV)-1 in type 1A curves with a neutral L3 vertebra, while it might be necessary to go down to the LEV with L3 vertebral tilt $^{45)}$. However, the selection of a proper LIV for thoracic major curves with lumbar modifier $\mathrm{C}$ remains controversial. Takahashi et al. ${ }^{52}$ focused on the choice of fusion levels in STF of AIS with Lenke type 1B, 1C, and 3C curves. They distinguished the curve patterns according to relative positions of the SV and the lower EV. If the SV was below the EV, the LIV should be chosen at or at least 1 level distal to the SV. If the SV and the EV are same, they recommended choosing the LIV to be 1 level below the SV/EV to achieve the greatest correction of both thoracic and lumbar curves, as well as trunk shift.

Matsumoto et al. ${ }^{35}$ investigated the occurrence of and factors related to postoperative adding-on in Lenke 1A curves. They suggested that the LIV should be extended to or beyond the last touched vertebra (LTV; the LIV that is touched by the CSVL) to avoid the development of postoperative adding-on. Fischer et al. ${ }^{11)}$, who evaluated the optimal LIV on the basis of rotation or CSVL, proposed that the LIV should be the LTV or within 2 levels proximal to the NV. Shen and colleagues argued that both SV and the last substantially touched vertebra (LSTV) can be applicable for the LIV and showed favorable outcomes in the management of Lenke 1A curves ${ }^{46}$. However, in comparison with the LSTV, the SV significantly decreases the occurrence of the adding-on phenomenon. In a recent study by Qin et al. ${ }^{42)}$, Lenke type 2 curves could be classified as $2 \mathrm{~A}-\mathrm{R}$ (L4 tilt to right) and 2A-L (L4 tilt to left) according to the direction of L4 vertebral tilt. They recommended extending the fusion level to the LSTV in 2A-R curves and to 1 level distal from the LSTV in 2A-L curves to avoid the distal adding-on phenomenon. The results of studies on LIV selection in AIS with thoracic curves are summarized in Table 4.

To summary, numerous studies have been conducted on the selection of the appropriate LIV in STF for avoiding com-
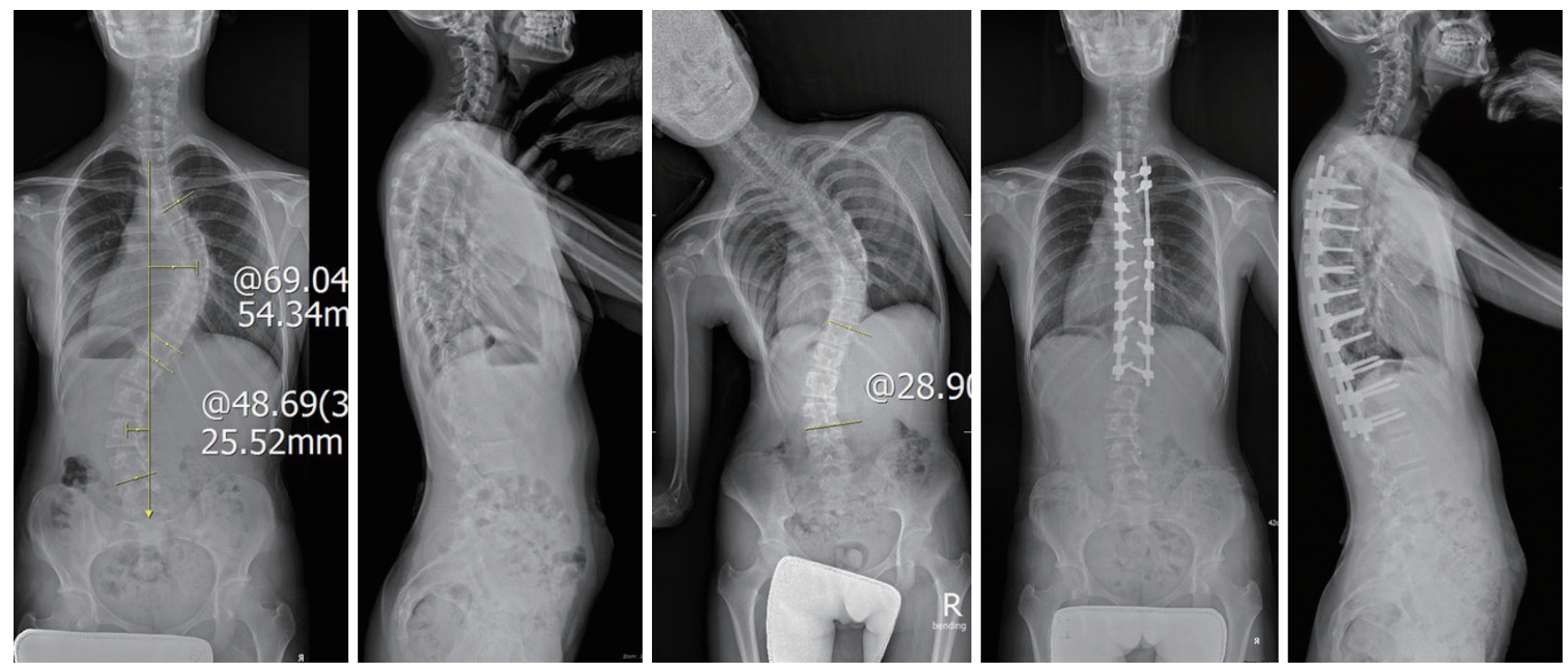

Fig. 2. A representative case of selective thoracic fusion for Lenke $3 C N$ curves. Preoperative standing posteroanterior radiography showed a right-side major thoracic curve of $69.0^{\circ}$ and a left-side structural lumbar curve of $48.6^{\circ}$, which was reduced by $28.9^{\circ}$ on the side bending film. The thoracic apical vertebral translation (AVT) was $54.3 \mathrm{~mm}$ and the lumbar AVT was $25.5 \mathrm{~mm}$. Considering that the upper end vertebra was T5 with level shoulders, T3 was chosen as the upper instrumented vertebra. The lower instrumented vertebra was located at L1, which was the last substantially touched vertebra by central sacral line. Therefore, the patient underwent selective thoracic fusion from T3 to L1. 
plications, such as adding-on and DJK, but this question remains controversial. Further comparative research on various criteria is required to improve long-term surgical outcomes (Fig. 2).

\section{Selective thoracolumbar or lumbar fusion}

\section{UIV}

The concept of minimizing the fusion levels and saving motion segments in TL/L curves are not new in the literature. Lenke et al. ${ }^{31}$, in their new surgical classification system, suggested that the UIV is often at the UEV of the TL/L curves, and Sanders and colleagues determined that if the ratio of the TL/L to thoracic Cobb angle magnitude is 1.25 or greater, the thoracic curve bends out to $20^{\circ}$ or less, and the triradiate cartilages are closed, TL/L selective fusion showed favorable outcomes and did not require further surgery ${ }^{44)}$.

Shufflebarger et al. ${ }^{47)}$ reported favorable outcomes of PSF for TL/L curves in AIS using a wide posterior release and posterior pedicle screws from the inferior EV to the UEV. According to long-term data reported by Bennett et al. ${ }^{2)}$, the UEV has usually been selected as the UIV in TL/L curves. A review article by Trobisch et al. ${ }^{54)}$ provided guidelines for Lenke $5 \mathrm{C}$ curves and recommended that the UEV should be used as the UIV unless it is not at the apex of the thoracic kyphosis. In 2014, Okada and colleagues ${ }^{39)}$ published the first comparative study addressing whether a short fusion strategy is applicable in Lenke $5 \mathrm{C}$ curves. They reported that not using the UEV as the UIV in Lenke 5C curves, but instead having the UIV be 1 level caudal to the UEV, is a reasonable alternative as a short fusion strategy ${ }^{39)}$. In 2016, Sudo et al. ${ }^{48)}$, who agreed with Okada et al. ${ }^{39)}$, reported that radiological and clinical outcomes did not differ according to whether the UIV was the UEV or 1 level caudal to the UEV. The results of studies on UIV selection in AIS with TL/L curves are summarized in Table 5 .

In summary, in the management of TL/L curves in AIS, some consensus has been reached regarding the selection of the UIV at 1 level caudal to the UEV as a short fusion strategy that can be an alternative to using the UEV.

\section{Lower instrumented vertebra}

For TL/L AIS, a short fusion strategy that saves the distal motion segment and reduces the risk of disc degeneration and low back pain is the goal of surgery. Some authors reported that no clinical and radiological differences were observed according to the distal fusion level (L3 vs. L4, LEV vs. LEV+1) ${ }^{8,51)}$. However, it is still believed that preservation of 1 more distal segment may be crucial for achieving a better long-term prognosis.

In 2014, Kim et al. ${ }^{24)}$ evaluated 66 patients with TL/L idiopathic scoliosis and suggested that L3 can be the LIV when the preoperative L3 crosses the mid-sacral line with rotation of less than grade II on bending radiographs. Otherwise, patients in whom fusion was extended to L4 showed satisfactory outcomes. In a subsequent study, Chang et al. ${ }^{3)}$ distinguished LIV selection in patients with TL/L idiopathic scoliosis according to the flexibility of the TL curve. If the curve is flexible (L3 crosses the CSVL with rotation < grade II), the LIV should be selected at L3 (LEV), while if the curve is rigid (L3 does not

Table 5. Summary of the literature on UIV selection in AIS with thoracolumbar/lumbar curves

\begin{tabular}{|c|c|c|c|c|c|}
\hline Study & Curve type & $\begin{array}{l}\text { Total No. } \\
\text { of patients }\end{array}$ & $\begin{array}{l}\text { Mean age } \\
\text { (years) }\end{array}$ & $\begin{array}{l}\text { Mean } \\
\text { follow-up } \\
\text { (years) }\end{array}$ & Conclusion \\
\hline Shufflebarger et al. ${ }^{47)}$ (2004) & Lenke $3 C, 5,6$ & 61 & - & Min. 2 & $\begin{array}{l}\text { Fusion from the inferior end vertebra to the UEV showed } \\
\text { excellent outcomes. }\end{array}$ \\
\hline Bennett et al. ${ }^{2)}$ (2013) & Lenke 3C, 5, 6 & 26 & 14.6 & Min. 5 & The UIV was usually selected to be the UEV in TL/L curves. \\
\hline Trobisch et al. ${ }^{54)}$ (2013) & Lenke 5 & - & - & - & $\begin{array}{l}\text { The UEV is recommended as the UIV unless it is not at the } \\
\text { apex of the thoracic kyphosis. }\end{array}$ \\
\hline Okada et al. ${ }^{39)}$ (2015) & Lenke 5 & 29 & 16.8 & 2.3 & $\begin{array}{l}\text { One level caudal to the UEV (UEV-1) is applicable to } \\
\text { posterior correction for Lenke } 5 \text { curves. }\end{array}$ \\
\hline Sudo et al. ${ }^{48)}(2016)$ & Lenke 5 & 30 & 14.4 & 17.2 & $\begin{array}{l}\text { One level caudal to the UEV (UEV-1) is a reasonable } \\
\text { alternative to the conventional strategy (UEV). }\end{array}$ \\
\hline
\end{tabular}

UIV : upper instrumented vertebra, AIS : adolescent idiopathic scoliosis, Min. : minimum, UEV : upper end vertebra, TL/L : thoracolumbar/lumbar 
cross the CSVL, or rotation $\geq$ grade II), the LIV should be lower, at L4 (LEV+1). Lee and colleagues ${ }^{30)}$ proposed that the LTV was an important factor affecting the optimal correction rate and progression of adjacent disc wedging. They recommended that if the LEV $\geq \mathrm{L} 3$ and the LTV $\geq \mathrm{L} 4$, distal fusion at L3 might be a good choice for saving lumbar motion segments. However, if LEV $\leq \mathrm{L} 4$ and LTV $=\mathrm{L} 5$, caution is required in selecting the distal fusion level. Recent studies of TL/L AIS also documented that stopping fusion at L3 or preserving 1 or 2 mobile segments showed similar clinical and radiological outcomes to those obtained with longer fusions ${ }^{7,20)}$. The results of studies on LIV selection in AIS with TL/L curves are summarized in Table 6.

Although controversies remain, there is agreement that fusion should be stopped at $\mathrm{L} 3$ if certain parameters are met in
TL/L idiopathic scoliosis. Further comparative, long-term follow-up studies are required to establish definitive guidelines for the selection of the distal fusion level of TL/L major curves.

\section{Coronal decompensation}

Coronal decompensation is a complication of corrective surgery for AIS. The Scoliosis Research Society (SRS) defines "decompensation" as a distance of more than $2 \mathrm{~cm}$ between the $\mathrm{C} 7$ plumb line and the central sacral vertical line ${ }^{23,33)}$. Care should be taken when choosing the UIV and LIV in selective fusion to prevent postoperative coronal decompensation. In the literature, coronal decompensation is thought to result from misinterpretation of the curvature, choice of an improper fusion level, incorrect rod derotation and direct vertebral rotation maneuvers, preoperative lumbar curve characteris-

Table 6. Summary of the literature on LIV selection in AIS with thoracolumbar/lumbar curves

\begin{tabular}{|c|c|c|c|c|c|}
\hline Study & Curve type & $\begin{array}{l}\text { Total No. } \\
\text { of patients }\end{array}$ & $\begin{array}{l}\text { Mean age } \\
\text { (years) }\end{array}$ & $\begin{array}{l}\text { Mean } \\
\text { follow-up } \\
\text { (years) }\end{array}$ & Conclusion \\
\hline Ding et al. ${ }^{8)}(2014)$ & - & 60 & 15.4 & Min. 2 & $\begin{array}{l}\text { There were no significant differences in clinical scores } \\
\text { between the L3 and the L4 group. }\end{array}$ \\
\hline Sun et al. ${ }^{51)}(2014)$ & Lenke 5 & 37 & 14.9 & 3.5 & $\begin{array}{l}\text { There was no benefit of fusing to } L E V+1 \text { in moderate } T L / L \\
\text { idiopathic scoliosis patients compared to fusing to } L E V \text {. } \\
\text { If the } T L / L \text { Cobb angle is more than } 60^{\circ} \text {, the distal fusion } \\
\text { level probably needs to be } L E V+1 \text {. }\end{array}$ \\
\hline Kim et al. ${ }^{24)}(2014)$ & Lenke 5 & 66 & 15.2 & Min. 2 & $\begin{array}{l}\text { Fusion to } L 3 \text { showed favorable radiographic outcomes } \\
\text { when } L 3 \text { crossed the mid-sacral line with rotation of less } \\
\text { than grade II in bending films. Otherwise, fusion has to } \\
\text { be extended to } L 4 \text {. }\end{array}$ \\
\hline Hyun et al. ${ }^{17)}(2015)$ & Lenke 5,6 & 76 & 14.7 & 3.2 & $\begin{array}{l}\text { To prevent } A O \text { or DJK following PSF to } L 3 \text {, the } C S V L \text { should } \\
\text { touch } L 3 \text { on upright and bending films, the } L 3 / 4 \text { disc } \\
\text { should be flexible, } L 3 \text { should be neutral }\left(<15^{\circ}\right) \text { and } \leq 2 \\
\mathrm{~cm} \text { from the } C S V L \text {, and patients should be } \geq \text { Risser } 2 \text {. }\end{array}$ \\
\hline Lee et al. $^{30)}(2016)$ & Lenke $3 C, 5,6$ & 229 & 15.6 & 3.7 & Fusion to $\mathrm{L} 3$ may be sufficient if $\mathrm{LEV} \geq \mathrm{L} 3$ and $\mathrm{LTV} \geq \mathrm{L} 4$. \\
\hline Chang et al. ${ }^{3)}(2017)$ & Major TL/L curves & 64 & 15.0 & Min. 2 & $\begin{array}{l}\text { If the curve is flexible ( } L 3 \text { crosses CSVL with a rotation } \\
<\text { grade II), LIV should be selected at } L 3 \text { (LEV). }\end{array}$ \\
\hline Ilharreborde et al. ${ }^{20)}(2017)$ & Lenke 5 & 78 & 16.0 & 4.6 & $\begin{array}{l}\text { Hyperselective (when the apex was located on a vertebral } \\
\text { body, fusion extended } 1 \text { vertebra below; while if the } \\
\text { apex was located on a disc, fusion extended } 2 \text { vertebrae } \\
\text { below) posterior fusions can be considered, preserving } \\
1 \text { or } 2 \text { mobile segments, with similar clinical and radiological } \\
\text { outcomes. }\end{array}$ \\
\hline Daher et al..$^{7)}(2019)$ & $\begin{array}{l}\text { Below } L 2 \text { with lumbar } \\
\text { modifier } B, C\end{array}$ & 25 & 15.2 & 3.2 & $\begin{array}{l}\text { Stopping fusion at } L 3 \text {, which presents similar clinical and } \\
\text { radiographical results in the short term, may be a good } \\
\text { option in order to save levels in the lumbar region. }\end{array}$ \\
\hline
\end{tabular}

LIV : lower instrumented vertebra, AIS : adolescent idiopathic scoliosis, Min. : minimum, LEV : lower end vertebra, TL/L : thoracolumbar/lumbar, AO : adding-on phenomenon, DJK : distal junctional kyphosis, PSF : posterior spinal fusion, CSVL : center sacral vertical line, LTV : last touched vertebra 
tics, and overcorrection ${ }^{43,50,61)}$.

Overcorrection of the primary thoracic or TL/L curve has been considered the most important factor related to coronal decompensation. Winter et al. ${ }^{59)}$ defined overcorrection as correction exceeding the flexibility of the main curve and stated and that it will cause problems in compensatory curves. Decompensation is believed to be worse when the thoracic or TL/L curve undergoes significant correction during surgery, but the compensatory curve is not spontaneously corrected well enough and is larger than the primary curve after selected thoracic or TL/L fusion. To achieve a well-balanced spine, surgeons should not perform correction in excess of preoperative flexibility and should avoid instrumentation within the "transitional mobile segments" that form the junction between the major and secondary curves ${ }^{53)}$. However, male sex, skeletal immaturity, and less correction of the major curve have been reported to be associated with a higher rate of coronal decompensation $^{13)}$. Thus, determining the appropriate amount of correction during surgery is important to prevent decompensation.

Another causative factor that contributes to decompensation is selection of an inappropriate fusion level. When performing STF, coronal decompensation is a major concern when the LIV is selected distal to the SV. Therefore many authors have suggested selecting the LIV at the SV in the thoracic major curve to avoid postoperative coronal decompensation $^{21,46,52)}$. Preoperative lumbar characteristics are also considered causative factors of coronal decompensation, but the details remain controversial. Liu et al. ${ }^{34)}$ claimed that preoperative LIV translation and LIV tilt are two important parameters that predict the immediate postoperative coronal balance. During postoperative follow-up, UIV tilt may play a highly important role in postoperative coronal decompensation in TL/L curves ${ }^{34)}$. Hwang et al. ${ }^{16)}$ proposed that less flexibility of the TL/L curve, greater TL kyphosis, and greater distal junctional angle were predictive factors for immediate coronal imbalance in Lenke 5C curves. However, coronal imbalance was corrected spontaneously with a decrease in the LIV tilt. Hence, they suggested that early postoperative coronal decompensation was not a significant factor affecting clinical outcomes.

Hyun and colleagues reported risk factors for distal addingon or DJK in AIS treated by posterior spinal fusion (PSF) to L3 with a minimum 2-year follow-up ${ }^{17,18)}$. In their series, the prevalence of distal adding-on or DJK at the final follow-up was $13.1 \%$. Multiple logistic regression analysis indicated that a preoperative Risser grade of 0 or 1 (odds ratio [OR], 1.8; $p=0.014), \mathrm{SV}-3$ at L3 in standing and side-bending (OR, 2.1 and $2.8 ; p=0.003$ and $p<0.001$, respectively), total stability scores of -5 or -6 at L3 (OR, $4.4 ; p<0.001)$, a rigid disc at L3-4 (OR, 3.1; $p<0.001)$, LIV rotation $>15^{\circ}(\mathrm{OR}, 2.9 ; p=0.001)$, and LIV deviation $>2 \mathrm{~cm}$ from CSVL (OR, $2.2 ; p=0.006)$ were independent predictive factors. Thus, the authors suggested that the CSVL should touch L3 on upright and bending films, the TS score should be -4 or less, the L3/4 disc should be flexible, L3 should be neutral $\left(<15^{\circ}\right)$ and $\leq 2 \mathrm{~cm}$ from the CSVL, and patients should be $\geq$ Risser 2 to prevent adding-on or DJK following PSF to L3. Interestingly, they also reported that the prevalence of adding-on or DJK at the final follow-up for AIS with LIV at L3 was significantly higher in patients who underwent anterior spinal fusion. In their series, the ultimate SRS-22 scores were significantly better in patients who underwent PSF. Thus, the authors suggested that if the LIV is L3, PSF is recommended to achieve the greatest correction of both thoracic and lumbar curves, as well as trunk shift, and to prevent adding-on or DJK following fusion to L3. However, due to the lack of research on definite radiological parameters and long-term follow-up data, the effects of preoperative parameters on coronal decompensation are still being debated.

\section{CONCLUSION}

The goal of corrective surgery for AIS is provide balanced curve correction while leaving the maximal possible number of mobile vertebral segments. Despite the continuing evolution of classification systems, improvements in instrumentation, and advances in surgical techniques, the choice of the correct fusion levels in AIS is still complex and a consensus has not been established. Based on the results of the studies that have been conducted so far, some agreement has been reached regarding the selection of the UIV in thoracic major curves and the UIV and LIV in TL/L major curves. However, the selection of an appropriate LIV in STF remains controversial, with considerable differences found among authors depending on their preferences in terms of radiographic parameters and complications to avoid. Definitive guidelines for choosing fusion levels in AIS have not been standardized. 
Coronal decompensation is a critical complication after corrective surgery in AIS. Causative factors that contribute to decompensation are male sex, skeletal immaturity, undercorrection or overcorrection, selection of an inappropriate fusion level, and preoperative clinical and radiographic characteristics. Therefore, spine surgeons should carefully consider the factors mentioned above when planning surgery.

Further research is needed to establish definitive guidelines for the selection of the fusion level in corrective surgery while minimizing coronal decompensation.

\section{CONFLICTS OF INTEREST}

No potential conflict of interest relevant to this article was reported.

\section{INFORMED CONSENT}

This type of study does not require informed consent.

\section{AUTHOR CONTRIBUTIONS}

\author{
Conceptualization : $\mathrm{SJH}$ \\ Data curation : DHK \\ Formal analysis : DHK \\ Funding acquisition : $\mathrm{SJH}$ \\ Methodology : DHK, SJH, KJK \\ Project administration : $\mathrm{SJH}$ \\ Visualization : DHK, SJH \\ Writing - original draft : DHK \\ Writing - review \& editing : SJH, KJK
}

\section{ORCID}

Do-Hyoung Kim https://orcid.org/0000-0002-0961-1807

Seung-Jae Hyun https://orcid.org/0000-0003-2937-5300

Ki-Jeong Kim

https://orcid.org/0000-0001-8547-8545

\section{References}

1. Akazawa T, Kotani T, Sakuma T, Minami S, Orita S, Fujimoto K, et al. : Spinal fusion on adolescent idiopathic scoliosis patients with the level of L4 or lower can increase lumbar disc degeneration with sagittal imbalance 35 years after surgery. Spine Surg Relat Res 1 : 72-77, 2017

2. Bennett JT, Hoashi JS, Ames RJ, Kimball JS, Pahys JM, Samdani AF : The posterior pedicle screw construct: 5 -year results for thoracolumbar and lumbar curves. J Neurosurg Spine 19 : 658-663, 2013

3. Chang DG, Yang JH, Suk SI, Suh SW, Kim YH, Cho W, et al. : Importance of distal fusion level in major thoracolumbar and lumbar adolescent idiopathic scoliosis treated by rod derotation and direct vertebral rotation following pedicle screw instrumentation. Spine (Phila Pa 1976) 42 : E890-E898, 2017

4. Chang KW, Leng X, Zhao W, Chen YY, Chen TC, Chang KI : Broader curve criteria for selective thoracic fusion. Spine (Phila Pa 1976) 36 : 1658-1664, 2011

5. Cil A, Pekmezci M, Yazici M, Alanay A, Acaroglu RE, Deviren V, et al. : The validity of Lenke criteria for defining structural proximal thoracic curves in patients with adolescent idiopathic scoliosis. Spine (Phila Pa 1976) $30: 2550-2555,2005$

6. Crawford CH 3rd, Lenke LG, Sucato DJ, Richards BS 3rd, Emans JB, Vitale MG, et al. : Selective thoracic fusion in Lenke $1 \mathrm{C}$ curves: prevalence and criteria. Spine (Phila Pa 1976) 38 : 1380-1385, 2013

7. Daher MT, Melo NC, Nascimento VN, Felisbino Jr P, AraÚJo BCR, Daher S, et al. : What is the best distal level of arthrodesis in lumbar fusion in patients with adolescent idiopathic scoliosis: L3 or L4? Coluna/Columna $18: 200-204,2019$

8. Ding R, Liang J, Qiu G, Shen J, Li Z : Evaluation of quality of life in adolescent idiopathic scoliosis with different distal fusion level: a comparison of L3 versus L4. J Spinal Disord Tech 27 : E155-E161, 2014

9. Elfiky TA, Samartzis D, Cheung WY, Wong YW, Luk KD, Cheung KM : The proximal thoracic curve in adolescent idiopathic scoliosis: surgical strategy and management outcomes. Global Spine J 1 : 27-36, 2011

10. Fischer $C R$, Kim $Y$ : Selective fusion for adolescent idiopathic scoliosis: a review of current operative strategy. Eur Spine J 20 : 1048-1057, 2011

11. Fischer CR, Lenke LG, Bridwell KH, Boachie-Adjei O, Gupta M, Kim YJ : Optimal lowest instrumented vertebra for thoracic adolescent idiopathic scoliosis. Spine Deform 6 : 250-256, 2018

12. Fruergaard S, Ohrt-Nissen S, Dahl B, Kaltoft N, Gehrchen M : Neural axis abnormalities in patients with adolescent idiopathic scoliosis: is routine magnetic resonance imaging indicated irrespective of curve severity? Neurospine $16: 339-346,2019$

13. Gomez JA, Matsumoto H, Colacchio ND, Roye DP Jr, Sucato DJ, Richards $B S$, et al. : Risk factors for coronal decompensation after posterior spinal instrumentation and fusion in adolescent idiopathic scoliosis. Spine Deform 2 : 380-385, 2014

14. Goshi K, Boachie-Adjei O, Moore C, Nishiyama M : Thoracic scoliosis fusion in adolescent and adult idiopathic scoliosis using posterior translational corrective techniques (Isola): is maximum correction of the thoracic curve detrimental to the unfused lumbar curve? Spine J 4 : 192- 
201, 2004

15. Harrington PR : Treatment of scoliosis. Correction and internal fixation by spine instrumentation. J Bone Joint Surg Am 44-A : 591-610, 1962

16. Hwang CJ, Lee CS, Kim H, Lee DH, Cho JH : Spontaneous correction of coronal imbalance after selective thoracolumbar-lumbar fusion in patients with Lenke-5C adolescent idiopathic scoliosis. Spine J 18 : 18221828, 2018

17. Hyun SJ, Lenke LG, Cerpa M, Kim YJ, Bridwell KH, Koester LA, et al. : Adolescent idiopathic scoliosis treated by posterior spinal segmental instrumented fusion: when is fusion to $\mathrm{L} 3$ stable? 22th International Meeting on Advanced Spine Techniques, 2015; Kuala Lumpur, Malaysia. Paper\#41

18. Hyun SJ, Lenke LG, Kim YJ, Bridwell KH, Koester LA, Blanke K : The prevalence of adding-on or distal junctional kyphosis in adolescent idiopathic scoliosis treated by anterior spinal fusion to $\mathrm{L} 3$ was significantly higher than by posterior spinal fusion to L3. SRS 53th Annual Meeting \& Course, 2018; Bologna, Italy. \#108

19. Iharreborde B, Even J, Lefevre $Y$, Fitoussi F, Presedo A, Souchet $P$, et al. : How to determine the upper level of instrumentation in Lenke types 1 and 2 adolescent idiopathic scoliosis: a prospective study of 132 patients. J Pediatr Orthop 28 : 733-739, 2008

20. Iharreborde $B$, Ferrero $E$, Angelliaume A, Lefèvre $Y$, Accadbled F, Simon $A L$, et al. : Selective versus hyperselective posterior fusions in Lenke 5 adolescent idiopathic scoliosis: comparison of radiological and clinical outcomes. Eur Spine J 26 : 1739-1747, 2017

21. Ishikawa M, Cao K, Pang L, Fujita N, Yagi M, Hosogane N, et al. : Onset and remodeling of coronal imbalance after selective posterior thoracic fusion for Lenke $1 C$ and 2 C adolescent idiopathic scoliosis (a pilot study).

Scoliosis Spinal Disord $12: 16,2017$

22. Joshi RS, Haddad AF, Lau D, Ames CP : Artificial intelligence for adult spinal deformity. Neurospine 16 : 686-694, 2019

23. Karami M, Maleki A, Mazda K : Assessment of coronal radiographic parameters of the spine in the treatment of adolescent idiopathic scoliosis.

Arch Bone Jt Surg 4 : 376-380, 2016

24. Kim SS, Lim DJ, Kim JH, Kim JW, Um KS, Ahn SH, et al. : Determination of the distal fusion level in the management of thoracolumbar and lumbar adolescent idiopathic scoliosis using pedicle screw instrumentation.

Asian Spine J 8 : 804-812, 2014

25. Kim YJ, Bridwell KH, Lenke LG, Kim J, Cho SK : Proximal junctional kyphosis in adolescent idiopathic scoliosis following segmental posterior spinal instrumentation and fusion: minimum 5-year follow-up. Spine (Phila Pa 1976) 30 : 2045-2050, 2005

26. Kim YJ, Hyun SJ, Cheh G, Cho SK, Rhim SC : Decision making algorithm for adult spinal deformity surgery. J Korean Neurosurg Soc 59 : 327333, 2016

27. King HA, Moe JH, Bradford DS, Winter RB : The selection of fusion levels in thoracic idiopathic scoliosis. J Bone Joint Surg Am 65 : 1302-1313, 1983

28. Kuklo TR, Lenke LG, Won DS, Graham EJ, Sweet FA, Betz RR, et al. : Spontaneous proximal thoracic curve correction after isolated fusion of the main thoracic curve in adolescent idiopathic scoliosis. Spine (Phila Pa 1976) 26 : 1966-1975, 2001

29. Lee CK, Denis F, Winter RB, Lonstein JE : Analysis of the upper thoracic curve in surgically treated idiopathic scoliosis. A new concept of the double thoracic curve pattern. Spine (Phila Pa 1976) 18 : 1599-1608, 1993

30. Lee CS, Ha JK, Hwang CJ, Lee DH, Kim TH, Cho JH : Is it enough to stop distal fusion at $\mathrm{L} 3$ in adolescent idiopathic scoliosis with major thoracolumbar/lumbar curves? Eur Spine J 25 : 3256-3264, 2016

31. Lenke LG, Betz RR, Harms J, Bridwell KH, Clements DH, Lowe TG, et al. : Adolescent idiopathic scoliosis: a new classification to determine extent of spinal arthrodesis. J Bone Joint Surg Am 83 : 1169-1181, 2001

32. Lenke LG, Bridwell KH, O'Brien MF, Baldus C, Blanke K : Recognition and treatment of the proximal thoracic curve in adolescent idiopathic scoliosis treated with Cotrel-Dubousset instrumentation. Spine (Phila Pa 1976) 19 : 1589-1597, 1994

33. Lenke LG, Edwards CC 2nd, Bridwell KH : The Lenke classification of adolescent idiopathic scoliosis: how it organizes curve patterns as a template to perform selective fusions of the spine. Spine (Phila Pa 1976) 28 : S199-S207, 2003

34. Liu Z, Guo J, Zhu Z, Qian B, Sun X, Xu L, et al. : Role of the upper and lowest instrumented vertebrae in predicting the postoperative coronal balance in Lenke $5 \mathrm{C}$ patients after selective posterior fusion. Eur Spine J 22 : 2392-2398, 2013

35. Matsumoto M, Watanabe K, Hosogane N, Kawakami N, Tsuji T, Uno K, et al. : Postoperative distal adding-on and related factors in Lenke type 1A curve. Spine (Phila Pa 1976) 38 : 737-744, 2013

36. Moe JH : A critical analysis of methods of fusion for scoliosis; an evaluation in two hundred and sixty-six patients. J Bone Joint Surg Am 40-A : 529-554 passim, 1958

37. Nash CL, Moe JH : A study of vertebral rotation. J Bone Joint Surg Am 51 : 223-229, 1969

38. Newton PO, Faro FD, Lenke LG, Betz RR, Clements DH, Lowe TG, et al. : Factors involved in the decision to perform a selective versus nonselective fusion of Lenke 1B and 1C (King-Moe II) curves in adolescent idiopathic scoliosis. Spine (Phila Pa 1976) 28 : S217-S223, 2003

39. Okada E, Watanabe K, Pang L, Ogura Y, Takahashi Y, Hosogane N, et al. : Posterior correction and fusion surgery using pedicle-screw constructs for Lenke type $5 \mathrm{C}$ adolescent idiopathic scoliosis: a preliminary report. Spine (Phila Pa 1976) 40 : 25-30, 2015

40. Parisini $P$, Di Silvestre $M$, Lolli F, Bakaloudis $G$ : Selective thoracic surgery in the Lenke type 1A: king III and king IV type curves. Eur Spine J 18 Suppl $1:$ : 82-88, 2009

41. Pham MH, Cerpa M, Makhni MC, Sielatycki JA, Lenke LG : Neurologic deficit during halo-gravity traction in the treatment of severe thoracic kyphoscoliotic spinal deformity. Neurospine 17 : 461-465, 2020

42. Qin $X$, He Z, Yin R, Qiu Y, Zhu Z : Selecting the last substantially touching vertebra as lowest instrumented vertebra in Lenke type $2 A-R$ and 2A-L curves. Spine (Phila Pa 1976) 45 : 309-318, 2020

43. Ries Z, Harpole B, Graves C, Gnanapragasam G, Larson N, Weintstein S, et al. : Selective thoracic fusion of Lenke I and II curves affects sagittal 
profiles but not sagittal or spinopelvic alignment: a case-control study. Spine (Phila Pa 1976) 40 : 926-934, 2015

44. Sanders AE, Baumann R, Brown $H$, Johnston CE 2nd, Lenke LG, Sink E : Selective anterior fusion of thoracolumbar/lumbar curves in adolescents: when can the associated thoracic curve be left unfused? Spine (Phila Pa 1976) 28 : 706-713; discussion 714, 2003

45. Sarlak AY, Atmaca H, Kim WJ, Musaoğlu R, Tosun B : Radiographic features of the Lenke $1 A$ curves to help to determine the optimum distal fusion level selection. Spine (Phila Pa 1976) 36 : 1592-1599, 2011

46. Shen M, Li N, Luo M, Xu G, Wang W, Wang L : Comparison of SV and LSTV as the lowest instrumented vertebra in Lenke $1 \mathrm{~A}$ adolescent idiopathic scoliosis: SV decreasing the distal adding-on phenomenon. Int J Clin Exp Med 11 : 9520-9527, 2018

47. Shufflebarger HL, Geck MJ, Clark CE : The posterior approach for lumbar and thoracolumbar adolescent idiopathic scoliosis: posterior shortening and pedicle screws. Spine (Phila Pa 1976) 29 : 269-276; discussion 276, 2004

48. Sudo H, Kaneda K, Shono $Y$, Iwasaki N : Selection of the upper vertebra to be instrumented in the treatment of thoracolumbar and lumbar adolescent idiopathic scoliosis by anterior correction and fusion surgery using dual-rod instrumentation: a minimum 12-year follow-up study. Spine J 16 : 281-287, 2016

49. Suk SI, Kim WJ, Lee CS, Lee SM, Kim JH, Chung ER, et al. : Indications of proximal thoracic curve fusion in thoracic adolescent idiopathic scoliosis: recognition and treatment of double thoracic curve pattern in adolescent idiopathic scoliosis treated with segmental instrumentation. Spine (Phila Pa 1976) 25 : 2342-2349, 2000

50. Suk SI, Lee SM, Chung ER, Kim JH, Kim WJ, Sohn HM : Determination of distal fusion level with segmental pedicle screw fixation in single thoracic idiopathic scoliosis. Spine (Phila Pa 1976) 28 : 484-491, 2003

51. Sun Z, Qiu G, Zhao Y, Wang Y, Zhang J, Shen J : Lowest instrumented vertebrae selection for selective posterior fusion of moderate thoracolumbar/lumbar idiopathic scoliosis: lower-end vertebra or lower-end vertebra+1? Eur Spine J 23 : 1251-1257, 2014

52. Takahashi J, Newton PO, Ugrinow VL, Bastrom TP : Selective thoracic fusion in adolescent idiopathic scoliosis: factors influencing the selection of the optimal lowest instrumented vertebra. Spine (Phila Pa 1976) 36 : 1131-1141, 2011

53. Thompson JP, Transfeldt EE, Bradford DS, Ogilvie JW, Boachie-Adjei O : Decompensation after Cotrel-Dubousset instrumentation of idiopathic scoliosis. Spine (Phila Pa 1976) 15 : 927-931, 1990

54. Trobisch PD, Ducoffe AR, Lonner BS, Errico TJ : Choosing fusion levels in adolescent idiopathic scoliosis. J Am Acad Orthop Surg 21 : 519528,2013

55. Wang T, Xu JG, Zeng BF : Selective fusion in adolescent idiopathic scoliosis. Chin Med J (Engl) 121 : 1456-1461, 2008

56. Wang Y, Hansen ES, Høy K, Wu C, Bünger CE : Distal adding-on phenomenon in Lenke $1 \mathrm{~A}$ scoliosis: risk factor identification and treatment strategy comparison. Spine (Phila Pa 1976) 36 : 1113-1122, 2011

57. Ward WT, Friel NA, Kenkre TS, Brooks MM, Londino JA, Roach JW : SRS-22r scores in nonoperated adolescent idiopathic scoliosis patients with curves greater than forty degrees. Spine (Phila Pa 1976) 42 : 1233-1240, 2017

58. Watanabe K, Aoki Y, Matsumoto M : An application of artificial intelligence to diagnostic imaging of spine disease: estimating spinal alignment from moiré images. Neurospine $16: 697-702,2019$

59. Winter RB, Lonstein JE, Denis $F$ : How much correction is enough? Spine 32: 2641-2643, 2007

60. Wui SH, Hyun SJ, Kang B, Kim KJ, Jahng TA, Kim HJ : Bicortical screw purchase at upper instrumented vertebra (UIV) can cause UIV fracture after adult spinal deformity surgery: a finite element analysis study. Neurospine 17 : 377-383, 2020

61. Zhao Y, Wang Z, Zhu X, Wang C, He S, Li M : Prediction of postoperative trunk imbalance after posterior spinal fusion with pedicle screw fixation for adolescent idiopathic scoliosis. J Pediatr Orthop B 20 : 199-208, 2011 